\title{
Application of Natural Coagulants as an Alternative to Alum for Wastewater Treatment
}

\author{
N. P., Sibiya, S, Rathilal, P., Govender and E. Kweinor Tetteh*
}

\begin{abstract}
Coagulation is one of the most widely used pre-treatment technology for water and wastewater treatment. Conventionally, metal-based coagulants (aluminum and iron) poses environmental challenges due to their complexity in biodegradation. Therefore, in this study, three natural-based coagulants (Egg shells, Rice starch and Bentonite) and Alum were evaluated for the removal of turbidity from simulated slaughterhouse wastewater. This was carried out at room temperature at a constant $\mathrm{pH}$ of 6.97. Each coagulant was then investigated within the dosage of $10-60 \mathrm{mg} / \mathrm{L}$ by using a Jar-test (JTL6). At the end of each run, the supernatant sample was analyzed in triplicate for turbidity (Hach DR3900). With the initial turbidity of $64.08 \mathrm{NTU}$, the order of maximum turbidity removal efficiencies by the coagulants were Bentonite $(98 \%)>$ Alum $(96 \%)>$ Rice starch $(85 \%)>$ Egg shell $(73 \%)$ at the optimum dosage of $30 \mathrm{mg} / \mathrm{L}$. Notwithstanding, all the natural coagulants showed great potential for the agglomeration and neutralization of the charges on the pollutants in the water, which might be due to their carboxylic and hydroxyl functional group constituents. In addition, there existed strong linear regression between the coagulant dosage and the turbidity removal, which makes the prospects of the natural coagulants economically viable for wastewater treatment.
\end{abstract}

Keywords-Alum, bentonite, coagulation, egg shells, natural coagulant, rice starch, wastewater

\section{INTRODUCTION}

Currently fresh water is depleting, the sources are running out and as a result 78 million people live without safe drinking water [1]. Also, fresh water demand increases exponentially with human population and industrial activities [2]. Therefore, treatment of wastewater for reuse comes in handy.

The numerous methods being used in treating wastewater is based on its toxicity in order to protect the aquatic systems [3], such as coagulation, adsorption, dissolved air flotation, membrane technology, biological systems, filtration and so on $[3,4,5]$. Coagulation has been a vital mechanism in physio-chemical wastewater treatment processes, which involves the addition of chemicals. Most of these chemicals are commonly known as coagulants (polymeric, natural, organic and inorganic) responsible for destabilizing and agglomerating the contaminants $[6,7,8]$. Generally, aluminum and iron-based coagulants (cheap) are employed in

Manuscript (EAP1120255) received September 22, 2020. This work was supported in part by Water Research Commission (WRC), South Africa and the for their support on the project identification WRC Project: C2019/2020-00212.

Faculty of Engineering and the Built Environment, Green Engineering and Sustainability Research Group, Department of Chemical Engineering, Durban University of Technology, Steve Biko Campus Block S4 Level 1, Box 1334, Durban 4000, South Africa (EKT) pre-treatment processes in water and wastewater treatment facilities to efficiently reduce the organic load prior to subsequent treatment processes $[3,7,8]$

However, these types of coagulants are associated with the formation of large volumes of sludge associated with complex metals. As a result, this poses great threat to agriculture, human health (memory loss, intestinal constipation, abdomen colic, spasms) and aquatic life if not treated before being disposed into the environment $[6,7,8]$. Therefore, the improvement of the coagulation process by the use of cost-effective or biodegradable or natural coagulants is worth investigating, since there is limited information and studies on natural coagulants used for wastewater treatment. This study investigated three natural-based coagulants (egg shells, rice starch and bentonite) and compared it with alum treatability performance for the removal of turbidity.

\section{Methodology}

\section{A. Chemicals and wastewater sample}

The 3 natural-based coagulant powders (egg shells, rice starch and bentonite) were laboratory prepared according to reported method by Jagaba et al [9]. Aluminum sulphate (alum) was supplied by Sigma Aldrich. Municipality based wastewater synthesized to have initial turbidity of 64.08 NTU was used.

\section{B. Jar test procedure}

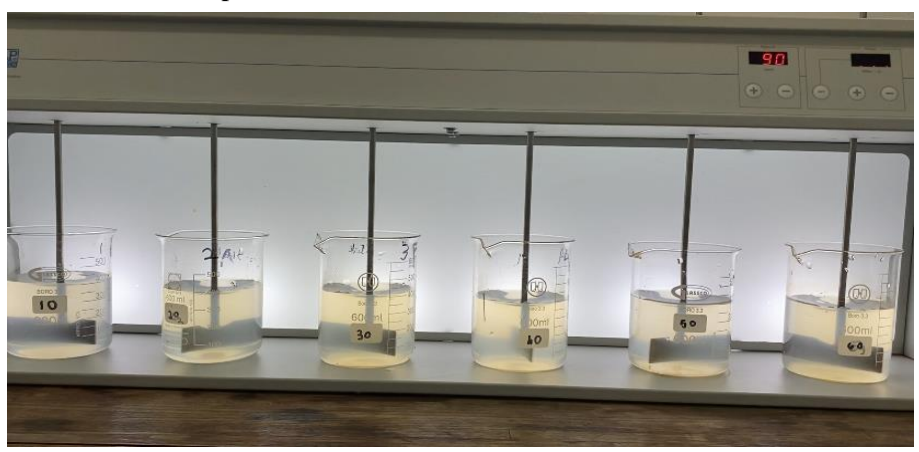

Fig 1 Schematic diagram of the programmable Jar test apparatus (JTL6)

The coagulation experiments were carried out using a jar-test (JT6L) apparatus coupled with six paddles (Fig 1). All the runs were carried out at an ambient temperature $\left(25 \pm 2^{\circ} \mathrm{C}\right)$. The wastewater samples were mixed thoroughly before being fractionated into beakers containing $500 \mathrm{~mL}$ of suspension each. After an addition of desired dosage for each coagulant (10 to $60 \mathrm{mg} / \mathrm{l}$ ) to the suspension, the beakers were agitated at rapid mixing $(90 \mathrm{rpm})$ for $2 \mathrm{~min}$ 
and slow mixing (30 rpm) for $15 \mathrm{~min}$. Thereafter, $15 \mathrm{~min}$ of motionless settling was allowed and then the samples were collected with a syringe at $2 \mathrm{~cm}$ beneath the surface for analysis.

\section{Turbidity analysis}

Turbidity was measured using the HI98703 turbidity meter, whereby the percentage removal was calculated according to equation (1).

$$
\begin{aligned}
& \text { Turbidity Removal }=\frac{T_{(\text {(initial) }}-T_{\text {(final) }}}{T_{\text {(inital) }}} \times 100 \\
& \text { Where: } \quad \mathrm{T}_{\text {(initial) }}=\text { Turbidity of Raw Water } \\
& \mathrm{T}_{\text {(final) }}=\text { Turbidity of Treated Water Sample }
\end{aligned}
$$

\section{RESULTS AND DISCUSSION}

As coagulation performance is mostly evaluated as a function of the dosage, inadequate and overdose of coagulants might result in poor performance $[7,8]$. In essence, determining the optimum dosage becomes crucial to improve the water quality and minimize the coagulant cost.

Therefore, in this study the performance of the coagulants were examined by varying their dosage from 10 to $60 \mathrm{mg} / \mathrm{L}$ for the removal of turbidity (Table 1).

TABLE I TURBIDITY RESULTS IN NTU FOR EACH NATURAL COAGULANT AT DIFFERENT DOSAGES

\begin{tabular}{lllll}
\hline \hline Dosage(mg/L) & Alum & Eggshell & $\begin{array}{l}\text { Rice } \\
\text { starch }\end{array}$ & Bentonite \\
\hline 10 & 4.15 & 40.8 & 25.9 & 7.79 \\
\hline 20 & 3.72 & 36.2 & 12.4 & 2.53 \\
\hline 30 & 2.72 & 17.5 & 9.55 & 2.10 \\
\hline 40 & 2.44 & 24.4 & 12.6 & 2.59 \\
\hline 50 & 1.51 & 17.5 & 13.7 & 4.96 \\
\hline 60 & 1.81 & 34.0 & 31.8 & 4.20 \\
\hline \hline
\end{tabular}

Fig 2 shows that increasing the coagulant dosage resulted in improvement of the turbidity removal (until a dosage of 30 $\mathrm{mg} / \mathrm{L})$ ). At dosages $>30 \mathrm{mg} / \mathrm{L}$, there was a reduction in the performance especially for the natural coagulants (Bentonite, Egg shells, and Rice starch) [9, 10]. Alum also shows an increase in coagulation activity when dosage increases. Therefore, it is important to determine optimum dosage to minimize dosing cost and sludge formation. Noticeably (Fig 2), at the dosage of $30 \mathrm{mg} / \mathrm{L}$, \%turbidity removal was at a maximum which corresponds to the optimal coagulant dosage. The order of maximum \%turbidity efficiencies by the natural coagulants were Bentonite $(97 \%)>>$ Rice starch $(85 \%)>$ Eggshells (73\%). Similarly, Tetteh and Rathilal [5] reported that increasing the coagulant dosage at a constant time increased the treatability performance of oil refinery wastewater using polymeric organic coagulants. In Fig 3, at the optimum dosage of $30 \mathrm{mg} / \mathrm{L}$, Bentonite $(97 \%)$ is seen to be the best alternative coagulant to alum $(96 \%)$, whereas Rice starch (85\%) and Eggshells (73\%) showed appreciable removal of the turbidity. This confirmed previous studies that an increase in the aforementioned coagulants increased the hydrolytic effect by producing more of the cationic charged species for the coalescing of the contaminants [8, 9. 10], Such that, there exits carbonyl $(\mathrm{C}=\mathrm{O})$, hydroxyl $(\mathrm{OH})$ and aliphatic amine $(\mathrm{N}-\mathrm{H})$ functional groups in the natural coagulants (Bentonite, Rice starch and Eggshells) [9,10]. According to Jagaba et al [9], these functional groups associated with cations and anions, made it possible for effective charge neutralization and agglomeration of the natural coagulants.

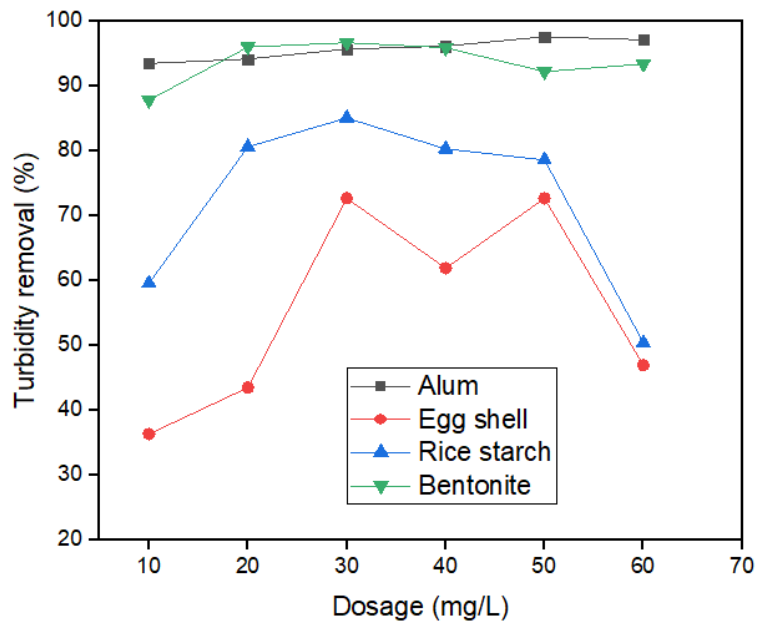

Fig 2 Effects of coagulant dosage (10-60 mg/L) on turbidity removal (\%) using different coagulant types

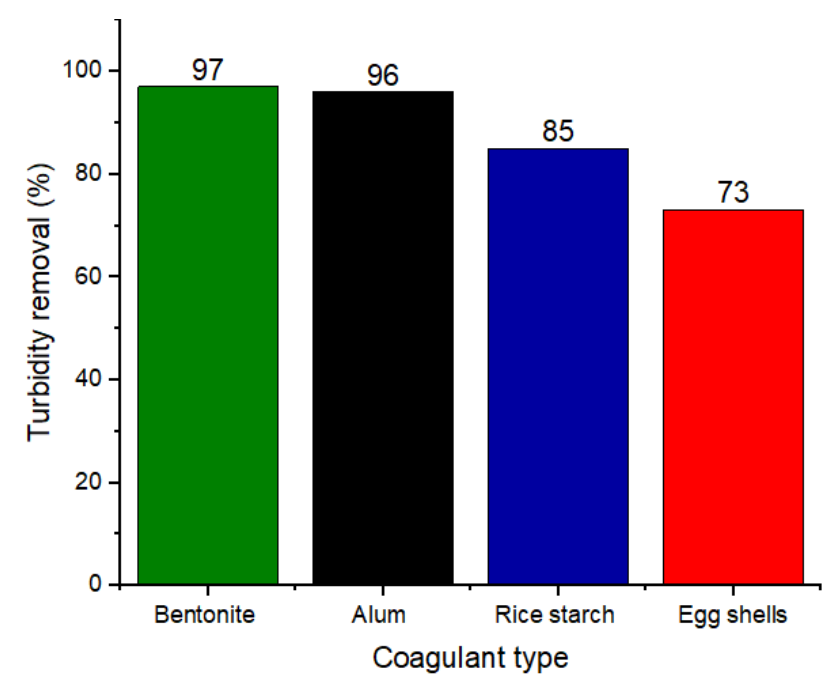

Fig 3 Performance of the coagulant at optimum dosage of $30 \mathrm{mg} / \mathrm{L}$ for the removal of turbidity; Bentonite $>$ Alum $>$ Rice starch $>$ Eggshells

As clearly seen in Fig 2 and 3, the coagulant dosage significantly affected the coagulation activity (turbidity removal). Conversely, it was being negatively affected by the high dosage (> $30 \mathrm{mg} / \mathrm{L}$ ). This phenomenon might be due to the occurrence of colloidal entrapment and high attractive force dominants. This proofs that the coagulation process is being controlled by charge neutralization and high bridging mechanism, which resulted in large aggregates formation and settling $[5,8,9]$. Also, the degree of coagulation is usually a function of time. Fig 4 also reveals reduction of the 
contaminants (turbidity) with an increase in time (5- $30 \mathrm{~min})$ at a constant dosage $(30 \mathrm{mg} / \mathrm{L})$. It was observed that the longer the settling time, the more clearly the treated water as the residual turbidity decreases. The sharp reduction with time is in accordance with the floc sweep or amalgamation of bridging - entrapment mechanism or theory proposed for rapid coagulation $[9,10]$. Furthermore, by using the Origin software (Version 2018, USA Inc.), as shown in Fig 4 (a) Bentonite $\left(\mathrm{R}^{2}=0.993\right)$, (b) Alum $\left(\mathrm{R}^{2}=0.984\right)$ and (c) Rice starch $\left(\mathrm{R}^{2}=0.999\right)$ were well fitted on logistic fit, whereas $(\mathrm{d})$ Egg shell $\left(\mathrm{R}^{2}=0.992\right)$ was fitted on the first order linear adsorption model. The high coefficient of determination $\left(\mathrm{R}^{2}\right)$ values obtained corroborated how the data well fitted on the model.

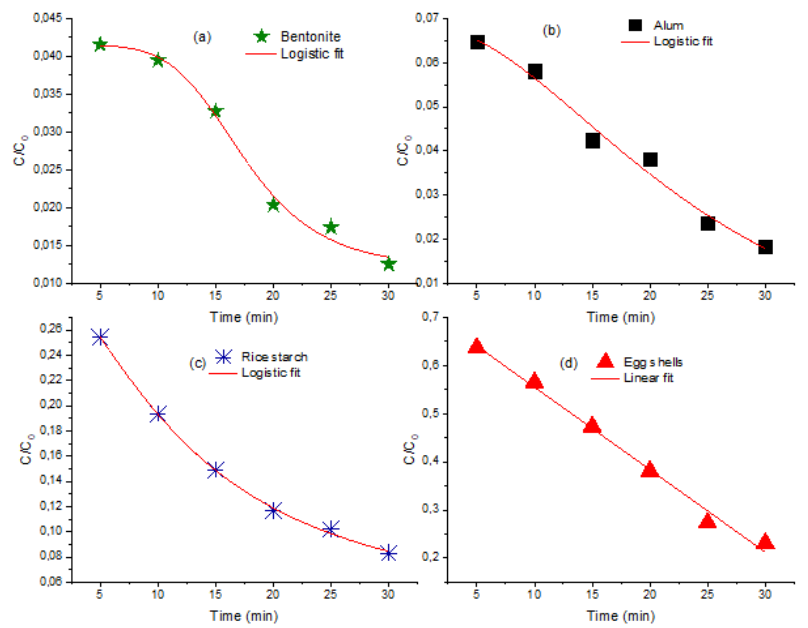

Fig 4 Turbidity reduction with respect to time (5 - $30 \mathrm{~min})$ at constant dosge of $30 \mathrm{mg} / \mathrm{L}$ fitted on Origin (Version 2018) model.

Generally, adding value to waste resources for reuse is gaining much attention, due to the environmental and socioeconomic values associated with them [9.10]. Therefore, using the aforementioned waste materials as coagulants are seen to be more advantageous to their chemical counterparts. Thus, they are cost-effective, non-corrosive, non-toxic, biodegradable and environmentally friendly. In addition, they produce minimal sludge with no complexity, which makes it possible to be use as fertilizer for agrochemicals $[4,7,9,10]$. However, these natural coagulants (Egg shells and Rice starch powder) so far are not commercialized except that of Bentonite [10]. This will therefore become a challenge for their industrial applications. .

\section{CONCLUSION}

This study investigated the viability of using three (3) natural coagulants or cost-effective materials as alternative coagulants to the application of alum coagulation in wastewater settings. In terms of their treatability performance at optimum dosage of $30 \mathrm{mg} / \mathrm{L}$, increasing their effective order was Bentonite $(98 \%)>$ Alum $(96 \%)>$ Rice starch $(85 \%)>$ Egg shell (73\%). Thus, Bentonite was the most effective while Egg shell showed appreciable coagulation activity. Also, the overdose (40-60 mg/L) caused destabilization of the particles due to reversal net charge. Furthermore, the results showed good correlation $\left(\mathrm{R}^{2}=0.85-0.99\right)$ and data fitness, hence the prospects of Rice starch and Eggshells have shown great potentials to be used as coagulation aids in wastewater setting.

\section{ACKNOWLEDGMENT}

The authors would like to express their gratitude to the Durban University of Technology, Green Engineering and Sustainability Research Group.

\section{REFERENCES}

[1] Bodlund, I. 2013. Coagulants protein from plant materials:Potential water treatment agent. Msc Biotechnology, Royal Institute of Technology.

Available:https://www.diva-portal.org/smash/record.jsf?pid=diva2\%3 A575557\&dswid=-1205 (Accessed 12 February 2020).

[2] A delodun, B., Ogunshina, M. S., Ajibade, F. O., Abdulkadir, T. S., Bakare, H. O. and Choi, K. S. 2020. Kinetic and prediction modeling studies of organic pollutants pemoval from municipal wastewater using Moringa oleifera Biomass as a coagulant. Water, 12: 1-14. https://doi.org/10.3390/w12072052

[3] Kukić, D., Šćiban, M., Prodanović, J., Vasić, V., Antov, M. and Nastić, N. 2018. Application of natural coagulants extracted from common beans for wastewater treatment. e-GFOS, 9 (16): 77-84. https://doi.org/10.13167/2018.16.7

[4] Tetteh, E.K. and Rathilal, S., 2019. Application of organic coagulants in water and wastewater treatment. IntechOpen

[5] Tetteh, E.K. and Rathilal, S., 2020. Evaluation of different polymeric coagulants for the treatment of oil refinery wastewater. Cogent Engineering, 7(1), p.1785756. https://doi.org/10.1080/23311916.2020.1785756

[6] Beyene, H. D., Hailegebrial, T. D. and Dirersa, W. B. 2016. Investigation of coagulation activity of cactus powder in water treatment. Journal of Applied Chemistry, 2016 (1): 1-9. https://doi.org/10.1155/2016/7815903

[7] Saifuddin, N. and Dinara, S. 2011. Pretreatment of palm oil mill effluent (POME) using magnetic chitosan. E-Journal of Chemistry, 8 (S1): S67-S78. https://doi.org/10.1155/2011/427532

[8] Teh, C.Y., Wu, T.Y. and Juan, J.C., 2014. Potential use of rice starch in coagulation-flocculation process of agro-industrial wastewater: treatment performance and flocs characterization. Ecological engineering, 71, pp.509-519. https://doi.org/10.1016/j.ecoleng.2014.07.005

[9] Jagaba, A. H., Latiff, A. A., Umaru, I., Abubakar, S. and Lawal, I. M. 2016. Treatment of palm oil mill effluent (POME) by coagulation-flocculation using different natural and chemical coagulants: A review. IOSR Journal of Mechanical and Civil Engineering, 13 (6): 67-75.

[10] Usefi, S. and Asadi-Ghalhari, M., 2019. Modeling and Optimization of the Coagulation-Flocculation Process in Turbidity Removal from Aqueous Solutions Using Rice Starch. Pollution, 5(3), pp.623-636. https://doi.org/10.1007/s42108-019-00010-2 